\title{
CLASSIFICAÇÃO DE SEMENTES DE ESPÉCIES FLORESTAIS DOS GÊNEROS Nectandra E Ocotea (LAURACEAE) QUANTO AO COMPORTAMENTO NO ARMAZENAMENTO'
}

\author{
LETICIA RENATA DE CARVALHO² ANTONIO CLAUDIO DAVIDE³ ${ }^{3}$ EDVALDO APARECIDO \\ AMARAL DA SILVA ${ }^{4}$, MARIA LAENE MOREIRA DE CARVALHO ${ }^{5}$
}

\begin{abstract}
RESUMO - O conhecimento do comportamento das sementes no armazenamento permite a utilização de condições adequadas para a manutenção de sua viabilidade, o planejamento de programas de produção de mudas e a conservação ex situ. O objetivo deste estudo foi o de classificar sementes de cinco espécies de Lauraceae de ocorrência no sul de Minas Gerais, Brasil, quanto ao comportamento no armazenamento. Sementes de Nectandra grandiflora, Nectandra lanceolata, Nectandra oppositifolia, Ocotea corymbosa e Ocotea pulchella foram submetidas à avaliação da germinação e do grau de umidade antes e após a secagem artificial. As sementes apresentam comportamento recalcitrante, devido à sensibilidade à secagem.
\end{abstract}

Termos para indexação: conservação, sensibilidade à dessecação.

\section{STORAGE BEHAVIOR OF FOREST SPECIES SEEDS OF OCOTEA AND NECTANDRA GENEROS (LAURACEAE).}

\begin{abstract}
Studies on seed storage behaviour allow the establishment of suitable conditions to maintain seed viability, in order to support programs of ex situ conservation and seedling production. Thus, this study aimed to investigate the seed storage behavior of five species of the Lauraceae family which grow in South of Minas Gerais State, Brazil. Seeds of Nectandra grandiflora, Nectandra lanceolata, Nectandra oppositifolia, Ocotea corymbosa and Ocotea pulchella were assessed regarding germination and moisture content before and after artificial drying. The seeds show recalcitrant behaviour due to their desiccation sensitivity.
\end{abstract}

Index Terms: conservation, desiccation sensitivity.

\section{INTRODUÇÃO}

O armazenamento de sementes permite a disponibilidade das mesmas aos programas de reflorestamento e pesquisas sobre tecnologia e fisiologia de sementes. Todavia, segundo Hong et al. (1996), o sucesso do armazenamento depende

${ }^{1}$ Submetido em 21/01/2007. Aceito para publicação em 25/07/2007.Parte da tese de doutorado do primeiro autor apresentada à UFLA.

${ }^{2}$ Engenheira Florestal, Dra - Departamento de Ciências Florestais/UFLA. Caixa Postal 3037, CEP 37200-000. Lavras, MG. drleticia2005@yahoo.com.br

${ }^{3}$ Eng. Agrônomo, Dr. Prof. Titular - Departamento de Ciências Florestais/ UFLA. acdavide@ufla.br do conhecimento prévio do comportamento fisiológico no armazenamento, já que sementes de diferentes espécies exigem condições especiais para a sua conservação.

Roberts (1973) classificou as sementes em dois grupos em relação à tolerância à secagem e a temperaturas baixa: sementes ortodoxas e recalcitrantes. Sementes ortodoxas

${ }^{4}$ Dr. Pesquisador/CNPq -Departamento de Engenharia Florestal/ UFLA. amaral@ufla.br.

${ }^{5}$ Engenheira agrônoma, Dra. Profa. - Departamento de agronomia/UFLA. mlaenemc@ufla.br 
toleram a secagem a baixos níveis de umidade e temperaturas baixas no armazenamento. Essas sementes podem ser secas até cerca de $5 \%$ de umidade, acondicionadas em embalagem hermética e submetidas à temperatura de $-18^{\circ} \mathrm{C}$, o que permite a conservação da viabilidade por longo prazo (IBPGR International Board for Plant Genetic Resources, citado pela FAO, 1993).

As sementes recalcitrantes não sobrevivem à secagem a baixos níveis de umidade e não podem ser armazenadas por longo prazo (Roberts, 1973). Um comportamento intermediário entre o ortodoxo e recalcitrante foi proposto por Ellis et al. (1990). Neste caso, as sementes toleram a desidratação somente até o grau de umidade entre 7,0\% e 10\% e não toleram temperaturas baixas por tempo prolongado. Esses três padrões de comportamento no armazenamento são encontrados em sementes de diferentes espécies tropicais (Hong e Ellis, 1996).

Existem sugestões de associação entre o comportamento das sementes no armazenamento e o grupo ecológico das espécies. Swaine e Whitmore (1988) propuseram um sistema para classificação das espécies em grupos ecológicos que as separa em dois grupos principais: espécies pioneiras e espécies clímax, sendo este último grupo subdividido em clímax exigente de luz e clímax tolerante à sombra, de acordo com a intensidade luminosa exigida para o crescimento das plântulas.

As sementes de espécies pioneiras necessitam de luminosidade intensa para a germinação, normalmente possuindo dormência e alta longevidade. Estas espécies regeneram-se por meio de banco de sementes e podem ser armazenadas por longo prazo (Kageyama e Viana, 1991), o que corresponde ao comportamento ortodoxo de armazenamento (Roberts, 1973). As espécies clímax, cujas sementes não necessitam de luz direta para germinação e crescimento da plântula, apresentam reduzida longevidade e regeneramse, principalmente, por meio de banco de plântulas. Dentro deste grupo podem ser encontradas sementes recalcitrantes que são ricas em lipídios (Kageyama e Viana, 1991).

Espécies clímax normalmente apresentam comportamento sazonal na produção de sementes (Bonner, 1990), o que dificulta a disponibilidade para atender aos programas florestais. A impossibilidade de conservação dessas sementes por longo prazo e a sazonalidade de produção podem tornar estas espécies mais vulneráveis a ações antrópicas e, conseqüentemente, mais susceptíveis ao processo de extinção. Dentre as espécies de Lauraceae ameaçadas de extinção encontram-se Nectandra grandiflora e Persea pyrifolia (SEMA, 2002).
A família Lauraceae possui 50 gêneros e cerca de 2.500 espécies amplamente distribuídas nas regiões tropicais e subtropicais, sendo que no Brasil ocorrem 22 gêneros e 390 espécies (Barroso et al., 2002). Levantamentos florísticos de remanescentes de florestas têm mostrado que a família Lauraceae destaca-se pelo grande número de espécies clímax, como foi verificado no planalto de Poços de Caldas (Souza, 1997) e no entorno de nascentes da sub-bacia do ribeirão Santa Cruz, município de Lavras, Sul de Minas Gerais (Pinto, 2003).

Informações sobre o comportamento no armazenamento de sementes de espécies de Lauraceae são escassas (Hong et al., 1996). Estes autores verificaram que, dentre 34 espécies, $74 \%$ apresentavam indícios de recalcitrância. Apenas duas tiveram sementes classificadas como possivelmente ortodoxas: Sassafras albidum e Cinnamomum camphora. No entanto, Chien e Lin (1999) enquadraram as sementes desta última espécie no grupo das intermediárias, devido à tolerância à secagem até $6,7 \%$ de umidade e alta sensibilidade à temperatura de $-20^{\circ} \mathrm{C}$. Da mesma forma, sementes de Neolitsea parvigemma, Lindera megaphylla e Cinnamomum subavenium também apresentaram características de comportamento intermediário (Lin, 1996).

No caso de espécies de Lauraceae nativas do Brasil, têm sido observadas sementes com comportamento recalcitrante (Carvalho, 1994; Davide et al., 2003). Apesar das pesquisas mostrarem que sementes de espécies de Lauraceae apresentam uma tendência à recalcitrância, o número de espécies estudadas é pequeno diante da grande diversidade de espécies. Além disso, segundo Hong e Ellis (1996), a classificação das sementes quanto ao comportamento no armazenamento depende do estudo de tolerância à secagem e à temperatura abaixo de zero.

Diante da crescente demanda de sementes de espécies nativas, pelo setor florestal, para atender aos programas de conservação e produção, este trabalho teve o objetivo de classificar as sementes de cinco espécies de Lauraceae quanto ao comportamento no armazenamento.

\section{MATERIAL E MÉTODOS}

Espécies estudadas e origem das sementes. $\mathrm{O}$ trabalho envolveu cinco espécies de Lauraceae dos gêneros Ocotea e Nectandra de ocorrência natural no Sul de Minas Gerais, nos municípios de Ijaci, Itumirim e Lavras (Tabela 1). O município de Ijaci encontra-se a $832 \mathrm{~m}$ de altitude, $21^{\circ} 10^{\prime} 13^{\prime}$ 'S de latitude e 4455'31'W de longitude. O município de Itumirim possui altitude de $870 \mathrm{~m}$ e está 
TABELA 1. Espécies estudadas, local de coleta, grupo ecológico, época de coleta e número de matrizes coletadas para cada espécie. CS: clímax tolerante à sombra; CL: clímax exigente de luz. (1) Oliveira-Filho et al., 1995; (2) Carvalho et al., 1999.

\begin{tabular}{|c|c|c|c|c|}
\hline $\begin{array}{l}\text { Nome científico } \\
\text { Nome vulgar }\end{array}$ & $\begin{array}{l}\text { Local de coleta } \\
\text { (município) }\end{array}$ & $\begin{array}{l}\text { Grupo ecológico } \\
\text { (referência) }\end{array}$ & Época de coleta & $\begin{array}{c}\text { Número de árvores } \\
\text { coletadas }\end{array}$ \\
\hline $\begin{array}{l}\text { Nectandra grandiflora Nees } \\
\text { Canela-fedida }\end{array}$ & Ijaci & CS (2) & $\begin{array}{l}\text { Dezembro } \\
2001\end{array}$ & 6 \\
\hline $\begin{array}{l}\text { Nectandra lanceolata Nees } \\
\text { Canela-cedro }\end{array}$ & Itumirim & CL (2) & $\begin{array}{l}\text { Janeiro } \\
2002\end{array}$ & 4 \\
\hline $\begin{array}{l}\text { Nectandra oppositifolia Nees } \\
\text { Canela-amarela }\end{array}$ & Lavras & CL (1) & $\begin{array}{l}\text { Novembro } \\
2001\end{array}$ & 1 \\
\hline $\begin{array}{l}\text { Ocotea corymbosa (Meisner) Mez } \\
\text { Canela-preta }\end{array}$ & Itumirim & CL (1) & $\begin{array}{l}\text { Setembro } \\
2003\end{array}$ & 2 \\
\hline $\begin{array}{l}\text { Ocotea pulchella Nees (Mez) } \\
\text { Canelinha }\end{array}$ & Lavras & CL (1) & $\begin{array}{l}\text { Setembro } \\
2003\end{array}$ & 4 \\
\hline
\end{tabular}

localizado a $21^{\circ} 19^{\prime} 02^{\prime}$ S de latitude e 4452'14'W de longitude (Coordenadoria Regional do Departamento de Estradas e Rodagem /MG, 2005). O município de Lavras possui altitude de $919 \mathrm{~m}$, encontra-se a $21^{\circ} 14^{\prime} \mathrm{S}$ de latitude e $45^{\circ} 00^{\prime} \mathrm{W}$ de longitude (Brasil, 1992a). O clima da região de Lavras é classificado como de transição entre Cwb e Cwa, ou seja, verões quentes e úmidos com inverno seco e moderado, de acordo com a classificação de Köppen (Köppen, 1936). A temperatura e a precipitação média anual são iguais a $19,4{ }^{\circ} \mathrm{C}$ e $1.529,7 \mathrm{~mm}$, respectivamente (Brasil, 1992a).

Coleta. As árvores de Nectandra grandiflora, Nectandra lanceolata, Ocotea corymbosa e Ocotea pulchella foram encontradas em agrupamentos. As árvores matrizes estavam distanciadas cerca de $50 \mathrm{~m}$, seguindo recomendações de Sebben (2002), com exceção para Ocotea corymbosa, cujas matrizes estavam distantes cerca de $30 \mathrm{~m}$ uma da outra. No caso de Nectandra oppositifolia, foi encontrada apenas uma matriz de ocorrência isolada. A colheita dos frutos foi realizada na época de dispersão, quando foi observada a queda espontânea. Os dados sobre a época de dispersão e o número de matrizes coletadas para a formação do lote de sementes de cada espécie encontram-se na Tabela 1. Durante a coleta, foi utilizado podão para cortar os ramos que continham frutos com diferentes colorações devido à irregularidade de maturação. Após a coleta, os frutos foram acondicionados em sacos de aniagem e transportados para o Laboratório de Sementes Florestais da Universidade Federal de Lavras. Foram utilizados aqueles que apresentaram coloração de frutos por ocasião da dispersão. Frutos de Nectandra oppositifolia e de Ocotea pulchella permaneceram acondicionados por 24 horas em sacos de aniagem e os de Nectandra grandiflora, Nectandra lanceolata e de Ocotea corymbosa permaneceram acondicionados por dois dias em sacos de aniagem, antes do beneficiamento.

Beneficiamento. Frutos de Ocotea corymbosa e de Ocotea pulchella foram umedecidos e acondicionados em saco plástico durante 24 horas para facilitar a remoção da polpa. Os frutos de todas as espécies foram macerados em peneira sob água corrente, para a eliminação da polpa. Após a remoção da polpa, as sementes foram lavadas em solução de hipoclorito de sódio $1,0 \%$, durante cinco minutos. Sementes que boiaram na solução foram descartadas e o restante foi enxaguado três vezes em água. O excesso de água foi retirado com papel toalha. $\mathrm{O}$ trabalho envolveu apenas sementes que não apresentaram danos visuais.

Determinação do número de sementes por kg. Inicialmente foi determinado o peso de 1.000 sementes, conforme as Regras para Análise de Sementes (Brasil, 1992b). Para todas as espécies foram utilizadas oito repetições de 100 sementes, com exceção de Nectandra oppositifolia, com quatro repetições. A partir do peso de 1.000 sementes foi calculado o número de sementes $/ \mathrm{kg}$.

Metodologia para a classificação das sementes quanto ao comportamento no armazenamento. Para a classificação 
das sementes foi utilizada a metodologia de acordo com o protocolo sugerido por Hong e Ellis (1996) (Figura 1).

Determinação do grau de umidade. O grau de umidade foi determinado antes e após a secagem. A determinação foi efetuada sob temperatura de $103^{\circ} \mathrm{C} \pm 2^{\circ} \mathrm{C}$, durante 17 horas. Os resultados foram expressos em porcentagem com base no peso úmido das sementes, conforme as Regras para Análise de Sementes (Brasil, 1992b). Para todas as espécies foram utilizadas quatro repetições. Para Ocotea pulchella foram utilizadas seis sementes, para Ocotea corymbosa foram utilizadas 10 sementes por repetição, cortadas transversalmente ao meio. Para Nectandra grandiflora, Nectandra lanceolata e Nectandra oppositifolia, foram utilizadas três sementes por repetição, que foram cortadas longitudinalmente e transversalmente ao meio.

Avaliação da viabilidade. A viabilidade das sementes foi determinada utilizando-se o teste de germinação antes e após a secagem. O teste foi realizado sobre areia que foi previamente autoclavada e molhada sempre que necessário. A germinação foi considerada como a formação de plântulas normais $(1 \mathrm{~cm}$ de epicótilo) quando foi possível visualizar os primórdios foliares. A temperatura utilizada foi $25^{\circ} \mathrm{C}$ sob luz constante, conforme Davide et al. (2003). Para cada espécie foram utilizadas quatro repetições de 20 sementes. Os testes foram finalizados quando ocorreu estabilização de germinação. Os dados sobre o período do teste, para cada espécie, encontram-se na Tabela 2.

Secagem das sementes. A secagem foi realizada em sala climatizada $\left(20^{\circ} \mathrm{C} ; 60 \% \mathrm{UR}\right)$, condição utilizada para a secagem de sementes destinadas ao armazenamento no

TABELA 2. Duração do período do teste de germinação e do período de secagem das sementes.

\begin{tabular}{lcc}
\hline Espécie & $\begin{array}{c}\text { Duração do } \\
\text { teste de } \\
\text { germinação } \\
\text { (dias) }\end{array}$ & $\begin{array}{c}\text { Período de } \\
\text { secagem } \\
\text { (dias) }\end{array}$ \\
\hline $\begin{array}{l}\text { Nectandra } \\
\text { grandiflora }\end{array}$ & 90 & 65 \\
$\begin{array}{l}\text { Nectandra } \\
\text { lanceolata }\end{array}$ & 100 & 65 \\
$\begin{array}{l}\text { Nectandra } \\
\text { oppositifolia } \\
\text { Ocotea corymbosa } \\
\text { Ocotea pulchella }\end{array}$ & 100 & 75 \\
\hline
\end{tabular}

Laboratório de Sementes Florestais da UFLA. Os dados sobre o tempo de secagem das sementes para cada espécie encontram-se na Tabela 2. As sementes foram pesadas diariamente com o objetivo de monitorar a perda de umidade utilizando-se a fórmula descrita por Hong e Ellis (1996).

Análise dos dados para a classificação das sementes quanto ao comportamento no armazenamento. Os dados de porcentagem de germinação foram interpretados conforme protocolo de classificação estabelecido por Hong e Ellis (1996), esquematizado na Figura 1.

\section{RESULTADOS E DISCUSSÃO}

As sementes apresentaram grau de umidade inicial variando de $38,3 \%$ para Ocotea corymbosa a 50,4\%, para Ocotea pulchella (Tabela 3). A condição de secagem utilizada $\left(20^{\circ} \mathrm{C}, 60 \% \mathrm{UR}\right)$ permitiu a redução do grau de umidade das sementes até a faixa de $10 \%$ a $15 \%$ de umidade. As sementes das espécies de Ocotea corymbosa e Ocotea pulchella tiveram o grau de umidade reduzido até a faixa de umidade proposta por Hong e Elllis (1996), ou seja, $11,6 \%$ e $10,7 \%$, respectivamente, enquanto que aquelas das espécies de Nectandra atingiram equilíbrio higroscópico com o grau de umidade mais elevado, ou seja, de $13,2 \%$ a $14,6 \%$, como observado para sementes de Nectandra oppositifolia e de Nectandra lanceolata, respectivamente (Tabela 3 ).

O grau de umidade mais elevado observado no ponto de equilíbrio higroscópico para as sementes de Nectandra pode ter ocorrido devido ao fato destas sementes serem maiores do que aquelas de espécies de Ocotea envolvidas no trabalho.

De acordo com Brasil (1992b) e ISTA (2004), sementes pequenas são aquelas que apresentam mais de 5.000 unidades/ $\mathrm{kg}$, enquanto que sementes grandes apresentam menos que 5.000 unidades $/ \mathrm{kg}$. Portanto, sementes das espécies de Nectandra grandiflora, Nectandra oppositifolia e de Nectandra lanceolata são consideradas grandes, enquanto que aquelas de Ocotea pulchella e de Ocotea corymbosa são pequenas (Tabela 3). Outro fator que pode ter interferido no grau de umidade atingido após a secagem é a constituição química dessas sementes. A constituição química dos tecidos das sementes é considerada como a principal interferência sobre o ponto de equilíbrio higroscópico em determinada condição de secagem (Von Pinho, 1998), ou seja, sementes oleaginosas atingem grau de umidade inferior em relação àquelas ricas em amido (Priestley, 1986, citado por Marcos Filho, 2005). 


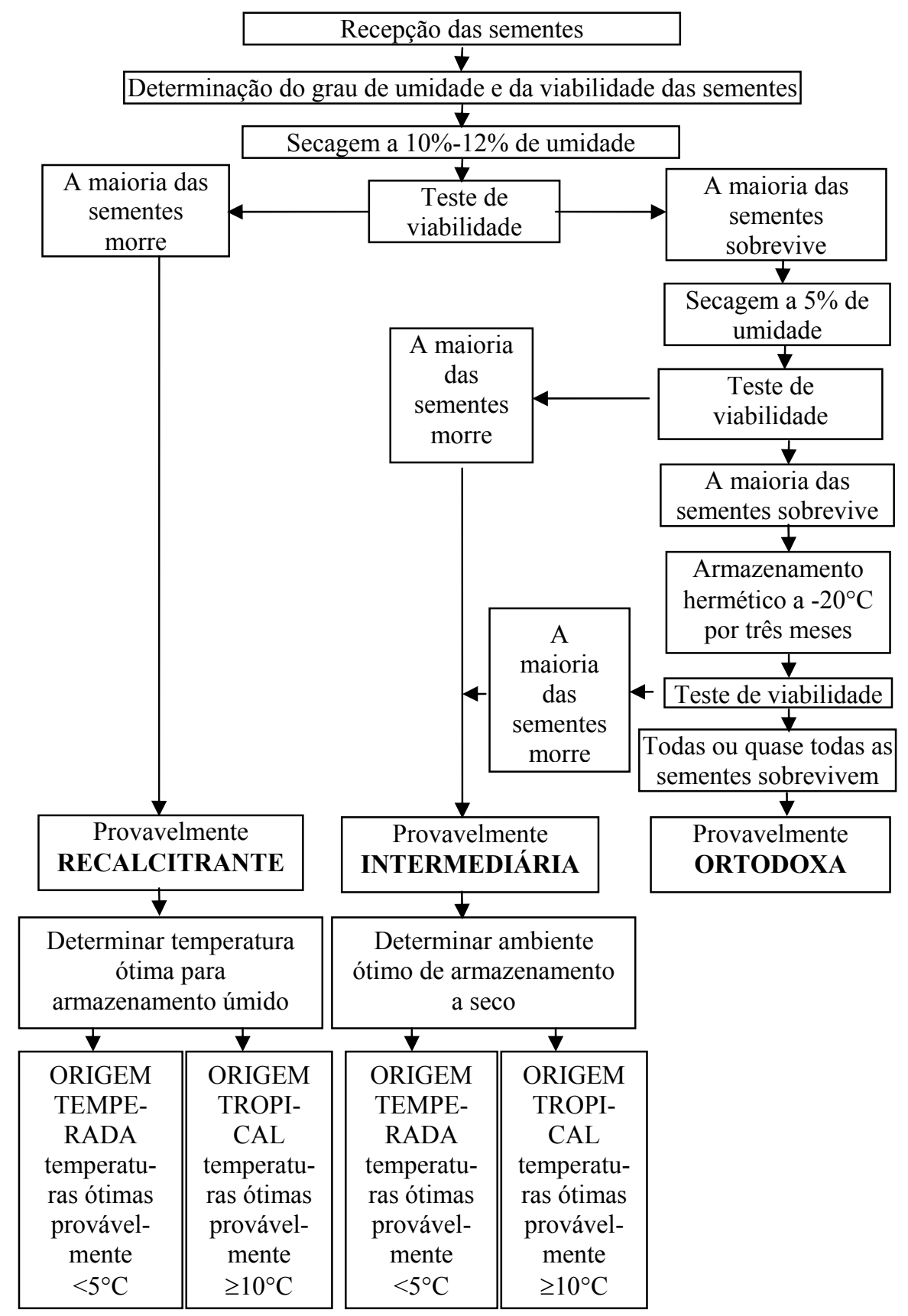

FIGURA1. Esquema simplificado do protocolo para determinar o comportamento de sementes no armazenamento (Hong e Ellis, 1996).

A germinação inicial das sementes variou de $73,8 \%$ a $80 \%$, como foi observado para sementes de espécies de Nectandra oppositifolia e Ocotea pulchella, respectivamente. As sementes das espécies do gênero Nectandra e de Ocotea pulchella apresentaram perda total de germinação após a secagem e sementes de Ocotea corymbosa apresentaram perda de 70 pontos percentuais da germinação inicial (Tabela
3). Assim, estas sementes foram enquadradas no grupo das provavelmente recalcitrantes, devido à sensibilidade à secagem, conforme Hong e Ellis (1996) (Figura 1).

Da mesma forma, Maluf et al. (2000) também sugeriram que sementes de Ocotea corymbosa possam ser recalcitrantes. Outras espécies pertencentes aos gêneros Ocotea e Nectandra também tiveram suas sementes classificadas como 
TABELA 3. Grau de umidade (U) e porcentagem de germinação (G) antes e após a secagem e número de sementes/kg das sementes das espécies estudadas.

\begin{tabular}{|c|c|c|c|c|c|}
\hline \multirow[t]{2}{*}{$\begin{array}{l}\text { Espécies } \\
\text { Nome científico }\end{array}$} & \multicolumn{2}{|c|}{ Sementes recém-beneficiadas } & \multicolumn{2}{|c|}{$\begin{array}{l}\text { Sementes } \\
\text { secas }\end{array}$} & \multirow[t]{2}{*}{$\begin{array}{l}\text { Número de } \\
\text { sementes/kg }\end{array}$} \\
\hline & $\begin{array}{c}\text { U (\%) } \\
\text { (desvio padrão) }\end{array}$ & $\mathrm{G}(\%)$ & $\mathrm{U}(\%)$ & $\mathrm{G}(\%)$ & \\
\hline \multirow[t]{2}{*}{ Nectandra grandiflora } & 42,8 & 76,3 & 13,7 & 0,0 & 462 \\
\hline & $(0,4)$ & $(2,5)$ & $(0,5)$ & - & \\
\hline \multirow[t]{2}{*}{ Nectandra lanceolata } & 41,3 & 76,3 & 14,6 & 0,0 & 950 \\
\hline & $(0,9)$ & $(8,5)$ & $(0,7)$ & - & \\
\hline \multirow[t]{2}{*}{ Nectandra oppositifolia } & 40,7 & 73,8 & 13,2 & 0,0 & 1.275 \\
\hline & $(0,6)$ & $(4,8)$ & $(0,6)$ & - & \\
\hline \multirow[t]{2}{*}{ Ocotea corymbosa } & 38,3 & 75,0 & 11,6 & 5,0 & 12.390 \\
\hline & $(0,2)$ & $(10,8)$ & $(0,6)$ & $(4,1)$ & \\
\hline \multirow[t]{2}{*}{ Ocotea pulchella } & 50,4 & 80,0 & 10,7 & 0,0 & 7.231 \\
\hline & $(0,6)$ & $(4,1)$ & $(0,4)$ & - & \\
\hline
\end{tabular}

recalcitrantes, a exemplo de Ocotea odorifera, Nectandra nitidula (Davide et al., 2003) e Nectandra membranaceae (González, 1991). Carvalho (1994) também afirmou que sementes de Ocotea catharinensis e de Ocotea puberula possuem curta longevidade quando armazenadas em condições não controladas. Banco de dados têm mostrado que sementes de outras espécies dos gêneros Ocotea e Nectandra podem ser recalcitrantes (Hong et al., 1996; Tweddle et al., 2005).

A condição de secagem utilizada neste trabalho permitiu uma secagem lenta, ou seja, o período de secagem variou de 50 dias, para sementes de Ocotea pulchella a 75 dias, para sementes de Nectandra oppositifolia (Tabela 2).

O desenvolvimento de sementes ortodoxas pode ser dividido em três fases principais: histo-diferenciação, maturação e secagem. Durante a fase de maturação, essas sementes adquirem tolerância à dessecação, que é mantida após a dispersão (Bewley e Black, 1994). A secagem até o grau de umidade de $5,0 \%$ a $15,0 \%$ pode levar as sementes ao estado de quiescência, o que causa redução do metabolismo até níveis mínimos, permitindo que elas permaneçam vivas, mesmo sob condições adversas. Após a hidratação, estas sementes podem retomar o metabolismo direcionado para o processo de germinação (Bewley e Black, 1994).

Por outro lado, sementes recalcitrantes não sofrem a secagem no final da maturação e são dispersas com elevado grau de umidade permanecendo metabolicamente ativas, sensíveis à secagem e podendo germinar logo após a dispersão (Faria et al., 2004; Farrant et al., 1986, Pammenter e Berjak, 2000).

A taxa de secagem pode influenciar na tolerância à dessecação. Por exemplo, para sementes ortodoxas de milho, a taxa de secagem lenta permitiu a indução de maior tolerância à dessecação (Rosa, 2000). Já para sementes recalcitrantes de Avicennia marina (Farrant et al., 1986) e Ekebergia capensis (Pammenter et al., 1998; Pammenter et al., 2000), e eixos embrionários de Trichilia dregeana, Castanospermum australe e de Camellia sinensis (Pammenter et al., 2000), a secagem rápida possibilita uma maior redução do grau de umidade antes da perda de viabilidade. O menor grau de umidade tolerado por estas sementes é sempre maior do que aquele tolerado pelas sementes ortodoxas ou intermediárias (Pammenter e Berjak, 1999). Pammenter et al. (2000) ressaltaram dois tipos de danos que ocorrem em sementes recalcitrantes quando submetidas à secagem lenta: danos relacionados a macromoléculas e danos decorrentes da manutenção das sementes em níveis intermediários de água, levando ao estresse oxidativo como conseqüência do metabolismo desregulado. Portanto, o protocolo para a classificação das sementes quanto ao comportamento no armazenamento deve considerar a taxa de secagem das sementes.

Sementes recalcitrantes de espécies tropicais têm sido caracterizadas como sementes grandes (Bonner, 1990; 
Kageyama e Viana, 1991). No entanto, espécies de Ocotea pulchella e Ocotea corymbosa possuem sementes pequenas, ou seja, 7.231 e 12.390 sementes $/ \mathrm{kg}$, respectivamente (Tabela 3). Da mesma forma, Davide et al. (2003) classificaram sementes de Persea pyrifolia e de Ocotea odorifera como recalcitrantes. Para estas espécies, foram verificadas 3.850 sementes $/ \mathrm{kg}$ e 4.550 sementes $/ \mathrm{kg}$, respectivamente (Davide et al., 1995). Portanto, estudos recentes envolvendo espécies florestais nativas do Brasil têm revelado a ocorrência de sementes pequenas com comportamento recalcitrante.

As espécies envolvidas neste trabalho pertencem ao grupo ecológico das clímax (Tabela 1). Os resultados deste trabalho estão de acordo com as sugestões de Kageyama e Viana (1991) e de Pammenter e Berjak (2000) de que sementes recalcitrantes são típicas de espécies clímax. Davide et al. (2003) também verificaram comportamento recalcitrante para as sementes de quatro espécies de Lauraceae pertencentes ao grupo ecológico das espécies clímax.

A irregularidade de frutificação, como foi observado para as espécies de Lauraceae envolvidas neste estudo, e para Ocotea catharinensis (Silva, 1997), aliada à tendência dessas espécies possuírem sementes recalcitrantes dificulta a disponibilidade de sementes aos programas florestais.

Sementes recalcitrantes podem ser armazenadas pelos métodos de armazenamento úmido, secagem parcial, condições de atmosfera controlada e criopreservação (Chin, 1995). A criopreservação tem se mostrado como a única alternativa promissora para a conservação por período prolongado, principalmente de eixos embrionários de sementes recalcitrantes (Pence, 1992; Chin, 1995). No entanto, esta técnica encontra-se em aperfeiçoamento e, dentre os aspectos que devem ser estudados, encontram-se as taxas de secagem e o conhecimento do grau crítico de umidade de eixos embrionários (Liang e Sun, 2000).

Estudos são necessários para determinar condições de armazenamento que possibilitem a manutenção da viabilidade de sementes recalcitrantes pelo maior período possível. Essas informações são importantes para os programas de produção de mudas, de forma a atender à crescente demanda, principalmente de projetos de recuperação de áreas degradadas.

\section{CONCLUSÃo}

As sementes das espécies Nectandra grandiflora, Nectandra lanceolata, Nectandra oppositifolia, Ocotea corymbosa e Ocotea pulchella apresentam comportamento de armazenamento recalcitrante.

\section{REFERÊNCIAS}

BARROSO, G. M.; GUIMARÃES, E. F.; ICHASO, C. L. F.; COSTA, C. G.; PEIXOTO, A. L. Sistemática de angiospermas do Brasil. 2. ed. Viçosa: UFV, 2002. v. 1, 309 p.

BEWLEY, J. D.; BLACK, M. Seeds: physiology of development and germination. New York: Plenum Press, 1994. $445 \mathrm{p}$.

BONNER, F. T. Storage of seeds: potential and limitations for germoplasm conservation. Forest Ecology and Management, Amsterdam, v. 35, n. 1/2, p. 35-43, June 1990.

BRASIL. Ministério da Agricultura e da Reforma Agrária. Normais Climatológicas 1961-1990. Brasília: DNDV/CLV, 1992a. 84 p.

BRASIL. Ministério da Agricultura e da Reforma Agrária. Regras para análise de sementes. Brasília: SNDA/DNDV/ CLAV, 1992b. 365 p.

CARVALHO, P. E. R. Espécies florestais brasileiras: recomendações silviculturais, potencialidades e uso da madeira. Brasília: EMBRAPA-SPI, 1994. 640 p.

CHIEN, C. T.; LIN, T. P. Effects of moisture content and temperature on the storage and germination of Cinnamomum camphora seeds. Seed Science and Technology, Zurich, v. 27, n. 2, p. 315-320, 1999.

CHIN, H. F. Storage of Recalcitrant Seeds. In: BASRA, A. S. Seed quality - basic mechanisms and agricultural implications. New York: The Haworth Press, 1995. p. 209-222.

COORDENADORIA REGIONAL DO DEPARTAMENTO DE ESTRADAS E RODAGEM/MG. 2005. Disponível em: http:// www.der.mg.gov.br/municípios>. Acesso em: 18 nov. 2005.

DAVIDE, A. C.; CARVAlHO, L. R. C.; CARVAlHO, M. L. M.; GUIMARÃES, R. M. Classificação fisiológica de sementes de espécies florestais pertencentes à família lauraceae quanto à capacidade de armazenamento. CERNE, Lavras, v. 9, n. 1, p. 29-35, 2003.

DAVIDE, A. C.; FARIA, J. M. R.; BOTELHO, S. A. Propagação de espécies florestais. Belo Horizonte: CEMIG/ UFLA/FAEPE; Lavras: UFLA, 1995. 41 p.

ELliS, R. H.; HONG, T. D.; ROBERTS, E. H. An intermediate category of seed storage behaviour? I. Coffee. Journal of Experimental Botany, Cambridge, v. 41, n. 230, p. 1167-1174, Sept. 1990.

FAO. Ex situ sorage of seeds, pollen and in vitro cultures of perennial woody plant species. Rome: FAO, 1993. 83 p. (FAO Foresty Paper, n. 113). 
FARIA, J. M. R.; LAMMEREN, A. A. M. van; HILHORST, H. W. M. Desiccation sensitivity and cell cycle aspects in seeds of Inga vera subsp. affinis. Seed Science Research, Wallingford, v. 14, n. 2, p. 165-178, June 2004.

FARRANT, J. M.; PAMMENTER, N. W.; BERJAK, P. The increasing desiccation sensitivity of recalcitrant Avicennia marina seeds with storage time. Physiologia Plantarum, Copenhagen, v. 67, n. 2, p. 291-298, June 1986.

GONZÁLEZ J. E. Contenido de humedad y germinacion de semillas de Virola koschnyi Warb. and Nectandra membranacea (Sw) Griseb. Brenesia, San Jose, v. 35, p. 8184, 1991.

HONG, T. D.; ELLIS, R. H. A protocol to determine seed storage behaviour. Rome: International Plant Genetic Resources Institute, 1996. 55 p. (IPGRI. Technical Bulletin, 1).

HONG, T. D.; LININGTON, S.; ELLIS, R. H. Seed storage behaviour: a compendium. Rome: International Plant Genetic Resources Institute, 1996. (IPGRI. Handbooks for Genebanks).

ISTA. International Rules for Seed Testing. Zürich, 2004. $180 \mathrm{p}$.

KAGEYAMA, P. Y.; VIANA, V. M. Tecnologia de sementes e grupos ecológicos de espécies arbóreas tropicais. In: SIMPÓSIO BRASILEIRO SOBRE TECNOLOGIA DE SEMENTES FLORESTAIS, 2., 1989, Atibaia, SP. Anais... São Paulo: Instituto Florestal, 1991. p. 197-215.

KÖPPEN, W. Das geographische system der klimate. In: KÖPPEN, W.; GEIGER, R. (Ed.). Handbuch der klimatologie. Berlin: Gebruder Borntraeger, 1936. v. 1, p. 1-44, part C.

LIANG, Y.; SUN, W. Q. Desiccation tolerance of recalcitrant Teobroma cacao embryonic axes: the optimal drying rate and its physiological basis. Journal of Experimental Botany, Cambridge, v. 51, n. 352. p. 1911-1919, 2000.

LIN, T. P. Seed storage behaviour deviating from the orthodox and recalcitrant type. Seed Science and Technology, Zurich, v. 24, n. 3, p. 523-532, 1996.

MALUF, A. M.; PASSOS, R.; BILIA, D. A. C.; BARBEDO,C. J. Longevidade e germinação dos diásporos de Ocotea corymbosa (Meissn) Mez. Scientia Agrícola, Piracicaba, v. 57, n. 1, p. 39-44, jan./mar. 2000.

MARCOS FILHO, J. Fisiologia de sementes de plantas cultivadas . Piracicaba: FEALQ. Biblioteca de Ciências Agrárias Luiz de Queiroz, 2005. v. 12, 495 p.

PAMMENTER, N. W.; BERJAK, P. A review of recalcitrant seed physiology in relation to desiccation-tolerance mechanisms. Seed Science Research, Wallingford, v. 9, n. 1, p. 13-37, Mar. 1999.

PAMMENTER, N. W.; BERJAK, P. Aspects of recalcitrant seed physiology. Revista Brasileira de Fisiologia Vegetal, Londrina, v. 12, p. 56-69, 2000. Edição Especial.

PAMMENTER, N. W.; BERJAK, P.; WALTERS, C. The effect of drying rate on recalcitrant seeds: "lethal water contents", causes of damage, and quantification of recalcitrance. In: BLACK, M.; BRADFORD, K. J.; VAZQUEZ-RAMOS, J. (Ed.). Seed biology: advances and applications. Wallingford: CABI Publishing, 2000. p. 215-221.

PAMMENTER, N. W.; GREGGAINS,V.; KIOKO, J. I.; WESLEY-SMITH, J.; BERJAK, P.; FINCH-SAVAGE, W. E. Effect of differential drying rates on viability retention of recalcitrant seeds of Ekebergia capensis. Seed Science Research, Wallington, v. 8, n. 4, p. 463-471, Dec. 1998.

PENCE, V.C.Desiccation and survival of Aesculus, Castanea, and Quercus embryo axes throught cryopreservation. Cryobiology, San Diego, v. 29, p. 391-399, 1992.

PINTO, L. V. A. Caracterização física da sub-bacia do Ribeirão Santa Cruz Lavras, MG, e propostas de recuperação de áreas no entorno de nascentes. 2003. 165 p. Dissertação (Mestrado) - Universidade Federal de Lavras, Lavras, 2004.

ROSA, S. D. V. F. da. Indução de tolerância à alta temperatura de secagem em sementes de milho por meio de pré-condicionamento a baixa temperatura. 2000. 121 p. Tese (Doutorado em Fitotecnia) - Universidade Federal de Lavras, Lavras, MG.

ROBERTS, E. H. Predicting the storage life of seeds. Seed Science and Technology, Zurich, v. 1, n. 4, p. 499514, 1973.

SEBBEN, A. M. Número de árvores matrizes e conceitos genéticos na coleta de sementes para reflorestamentos com espécies nativas. Revista do Instituto Florestal, São Paulo, v. 14, n. 2, p. 115-132, dez. 2002.

SEMA (Secretaria estadual do meio ambiente). Lista das espécies da flora ameaçadas de extinção do Rio Grande do Sul, 2002. Disponível em: <http://www.sema.rs.gov.br/sema/ html/pdf/espéciesameaçadas.pdf>. Acesso em: 15 dez. 2005.

SILVA, A. da Padrão de florescimento e frutificação, caracterização de diásporos e germinação de sementes de canela-preta (Ocotea catharinensis Mez.). 1997. 94 p. Dissertação (Mestrado) - Universidade Estadual Paulista. Faculdade de Ciências Agrárias e Veterinária, Jaboticabal, 1997. 
SOUZA, J. A. de Avaliação das estratégias de recuperação de áreas degradadas pela mineração de bauxita em Poços de Caldas (MG). 1997. 104 p. Tese (Doutorado em Agronomia) - Universidade Federal de lavras, Lavras, MG.

SWAINE, M. D.; WHITMORE, T. C. On the definition of ecological species groups in tropical rain forests. Vegetatio, Dordrecht, v. 75, n. 1/2, p. 81-86, May 1988.
TWEDDLE, J. C.; TURNER, R. M.; DICKIE, J. B. 2003. Seed Information Database. Disponível em: <http://www.kew.org/sid>. Acesso em: 20 nov. 2005 .

VON PINHO, E. V. de R. A secagem de sementes:curso de especialização pós-graduação "Lato Senso" por tutoria à distância. Lavras: UFLA-FAEPE, 1998.72p. 